Bond University

Research Repository

\title{
Relationship Between the 20-m Multistage Fitness Test and 2.4-km Run in Law Enforcement Recruits
}

Lockie, Robert G; Dawes, J Jay; Moreno, Matthew R; Cesario, Karly A; Balfany, Katherine; Stierli, Michael; Dulla, Joseph M; Orr, Robin M

Published in:

Journal of Strength and Conditioning Research

DOI:

10.1519/JSC.0000000000003217

Licence:

Other

Link to output in Bond University research repository.

Recommended citation(APA):

Lockie, R. G., Dawes, J. J., Moreno, M. R., Cesario, K. A., Balfany, K., Stierli, M., Dulla, J. M., \& Orr, R. M.

(2019). Relationship Between the 20-m Multistage Fitness Test and 2.4-km Run in Law Enforcement Recruits. Journal of Strength and Conditioning Research. https://doi.org/10.1519/JSC.0000000000003217

\section{General rights}

Copyright and moral rights for the publications made accessible in the public portal are retained by the authors and/or other copyright owners and it is a condition of accessing publications that users recognise and abide by the legal requirements associated with these rights.

For more information, or if you believe that this document breaches copyright, please contact the Bond University research repository coordinator. 
Relationship between the 20-meter Multistage Fitness Test and 2.4-kilometer Run in Law Enforcement Recruits 


\section{ABSTRACT}

In the USA the 2.4-km run is arguably the most common law enforcement aerobic assessment. Potential limitations are that recruits use an internal pacing strategy, the test requires fewer direction changes, and less fit recruits run for longer. The 20-m multistage fitness test (20MSFT) is commonly used internationally to assess aerobic fitness in law enforcement recruits, and provides an external pacing strategy. This study documented sex differences between the 2.4-km run and 20MSFT in law enforcement recruits, and between-test relationships. Retrospective analysis on eight academy classes (463 males, 87 females) from one agency was conducted. The 20MSFT was completed prior to academy; the 2.4-km run in the first week. Between-sex comparisons in the 2.4-km run and 20MSFT were conducted with independent samples t-tests and effect sizes. Estimated $\dot{\mathrm{V}}_{2 \max }$ from the tests was compared with paired samples t-tests. Correlations and linear regression calculated $2.4-\mathrm{km}$ run and 20MSFT relationships. There were significant between-sex differences for the $2.4-\mathrm{km}$ run and 20MSFT $(p<0.01)$, with moderate $(d=0.9)$ and small $(d=0.4)$ effects, respectively. Estimated 2.4-km run $\dot{\mathrm{VO}}_{2 \max }$ was greater than that from the 20MSFT $(p<0.01)$. The 2.4-km run had significant relationships with the 20MSFT $(r=-0.6)$, although the regression equations were low $\left(r^{2}=0.30-0.37\right)$. Between-sex differences in the 20MSFT appeared less than for the 2.4$\mathrm{km}$ run. Nonetheless, even with significant relationships between the tests, the 20MSFT induces a higher running intensity and direction changes. This may limit transferability with the 2.4-km run in law enforcement recruits.

Key words: 1.5 -mile run; cardiorespiratory fitness; maximal aerobic capacity; occupational testing; police; tactical 


\section{INTRODUCTION}

Law enforcement can be a physically demanding profession for incumbent officers. At any time during a shift, an on-duty officer may be required to push, pull, lift, carry, drag, jump, vault, crawl, and sustain pursuit of a suspect $(10,42)$. A physiological foundation for these tasks, especially if they are completed in succession, or need to be sustained for an extended period of time, is aerobic fitness (4). In addition to benefitting job task performance, superior aerobic fitness has been linked to a reduced risk of cardiovascular disease $(14,20,21)$. This is notable in law enforcement populations due to the high incidence of these diseases in incumbent officers (45). At the recruit level, higher aerobic fitness as measured by the 2.4kilometer $(\mathrm{km})$, or 1.5-mile run, has been related to successful graduation from academy training (38).

Most law enforcement agencies (LEAs) have some form of aerobic fitness testing as part of the hiring process for potential recruits. In the USA, arguably the most common test is the $2.4-\mathrm{km}$ run $(7,8,10,12,25-27,32,38,42)$. The $2.4-\mathrm{km}$ run involves staff measuring the requisite distance within the confines of the training facility $(25,27)$ or neighboring streets (depending on the road grade and weather) to the facility (8), and timing how long it takes a recruit to complete the run. This test is relatively easy to conduct and provides a valid measure of aerobic capacity (15). However, the $2.4-\mathrm{km}$ run as it pertains to law enforcement fitness is not without limitations. Individuals will typically use an internal pacing strategy where they find a comfortable cadence during an extended run (41), as this will allow them to complete the run in the most efficient manner as possible. However, finding this optimal pace can be challenging for some tactical personnel (1). In addition to this, many essential law enforcement tasks (e.g., suspect pursuit and restraint) are externally paced, which reduces validity relative to the demands of the 2.4-km run. Furthermore, the $2.4-\mathrm{km}$ run requires few direction changes depending on where the test is conducted. Although this reduces the stress encountered during 
the run for the officers (30), the lack of direction changes may contribute to reduced validity as it relates to law enforcement job demands. Finally, as the $2.4-\mathrm{km}$ is a timed event over a given distance, less fit individuals will place their cardiovascular system under stress for longer when compared to their fitter counterparts.

Accordingly, there are available aerobic fitness tests that provide an external pacing stimulus. One example is the multistage fitness test (MSFT) (22), which is a shuttle run test conducted over 15-20 meters (m) with progressive increases in speed every minute. The MSFT is commonly used in the assessment of law enforcement recruits in the United Kingdom (UK) (4) and Australia $(33,34,37)$, and has been adopted by some agencies in the USA $(11,12,30)$. The MSFT has the advantage of forcing individuals to increase their running cadence during the test, before the number of successful shuttles is recorded as the score $(12,30,34)$. This may also provide a better relationship to their future occupation for law enforcement recruits, as many of their job tasks and 'real-world' situations are externally-paced (4). The 20-m MSFT (20MSFT) has been shown to be a valid measure of aerobic capacity in adult populations $(28,36)$, performance in this test has been linked to faster load carriage performance in specialist police officers (37), and this test can be conducted over a smaller area compared to the 2.4-km run. Further, the nature of the test means that the less fit officers stop sooner, which may provide a safety benefit given that incumbent officers can be at a greater risk of cardiovascular disease (45). Even so, LEA staff should be cognizant that the 20MSFT places a greater demand on an individual's ability to complete high-intensity running. Due to the progressive increase in speed, individuals must have the capacity to run at the faster speeds required within the 20MSFT. An inability to keep pace means individuals could be ejected from the test even if they have not reached their maximal aerobic capacity (40). Accordingly, the physiological qualities needed for superior 20MSFT performance could be disparate to that for the 2.4-km run in law enforcement recruits. 
There is a lack of uniformity in fitness testing across LEAs in the USA, with legal requirements varying from state-to-state and county-to-county. This makes it challenging to compare data across agencies if different fitness tests are used, and to historically compare data within an agency if fitness tests change. Both the 2.4-km run (15) and 20MSFT (36) can be used to estimate maximal aerobic capacity, although anecdotally it can be viewed that the running demands are different (i.e., internal vs. external pacing). Previous research in UK military personnel has illustrated a strong linear relationship between these tests for both men and women (43). Indeed, Wilkinson et al. (43) was able to generate a predictive equation for the 20MSFT based on 2.4-km run time: MSFT shuttles $=(9.708 \times 2.4-\mathrm{km}$ run speed $)-52.56$. However, the relationship between these two tests has not been investigated in law enforcement populations from the USA. This is important information to obtain, as any LEA staff that transitions between these two tests should know whether they assess similar physical capacities specific to their recruits or incumbents. Furthermore, establishing any relationship (or lack thereof) between the two tests could illustrate whether certain training practices are appropriate if either is used as an entry requirement for recruits. It could be argued that the traditional law enforcement academy training model, which often includes long, slow distance and continuous running $(6,29,33)$, would be more related to $2.4-\mathrm{km}$ run performance. In contrast, interval training, or the interspersing of high-intensity efforts during training, could be more related to the 20MSFT, and arguably, many law enforcement tasks as well $(4,8,23)$.

Therefore, this study investigated the relationships between $2.4-\mathrm{km}$ run times and 20MSFT shuttles in male and female LEA recruits prior to academy training. A cross-sectional and retrospective analysis of pre-existing data collected from LEA recruits was conducted. Although estimated maximal aerobic capacity $\left(\dot{\mathrm{V}}_{2 \mathrm{max}}\right)$ as derived from each of these tests was included in the study for the purposes of analysis, the goal of this research was not to determine a 'gold-standard' for $\dot{\mathrm{V}} \mathrm{O}_{2 \max }$. This was primarily due to the fact that LEAs do not use $\dot{\mathrm{V}} \mathrm{O}_{2 \max }$ 
as part of hiring standards; rather, agencies either use the $2.4-\mathrm{km}$ run time $(7,8,10,12,25-$ $27,32,38,42)$ or number of MSFT shuttles completed $(4,11,12,30,33,34,37)$ as the indicator for aerobic fitness. Similar to previous research on law enforcement recruits and incumbents $(3,7,12,24,27)$, it was hypothesized that males would perform significantly better in both the 2.4-km run and 20MSFT compared to females. It was further hypothesized that in line with the results from Wilkinson et al. (43), there would be a significant relationship between the two tests, and that predictive equations could be generated via linear regression.

\section{METHODS}

\section{Experimental Approach to the Problem}

A retrospective analysis of existing data was conducted to investigate the relationships between the 2.4-km run and 20MSFT in LEA recruits. Firstly, a between-sex analysis of each test was conducted to see if either the 2.4-km run or 20MSFT had a greater disparate impact on females compared to males (3). Estimated $\dot{\mathrm{VO}}_{2 \max }$ for the 2.4-km run and 20MSFT were also calculated to allow for further comparison between the aerobic fitness measures. Lastly, the relationship between the two tests was investigated with Pearson's correlations and linear regression. The dependent variables for this study were the $2.4-\mathrm{km}$ run time and number of 20MSFT shuttles, in addition to estimated $\dot{\mathrm{V}} \mathrm{O}_{2 \max }$ derived from each test.

\section{Subjects}

Retrospective analysis on recruits from eight academy classes from one agency was conducted. This sample was comprised of 550 recruits (age: $27.12 \pm 5.68$ years; height: $1.74 \pm 0.11 \mathrm{~m}$; body mass: $80.80 \pm 14.24 \mathrm{~kg}$ ), which included 463 males (age: $27.10 \pm 5.77$ years; height: 1.76 $\pm 0.10 \mathrm{~m}$; body mass: $83.64 \pm 12.71 \mathrm{~kg}$ ) and 87 females (age: $27.24 \pm 5.17$ years; height: 1.63 $\pm 0.07 \mathrm{~m}$; body mass: $65.73 \pm 12.37 \mathrm{~kg}$ ). The eight training cohorts started their academy within 
a calendar year in southern California. Any strength and conditioning programs prior to academy were generally completed voluntarily at the individual-level only by recruits. Based on the archival nature of this analysis, the institutional ethics committee approved the use of pre-existing data.

\section{Procedures}

The data in this study were collected by staff working for one LEA. The staff were all trained by a certified tactical strength and conditioning facilitator (TSAC-F) who verified the proficiency of the staff members. The 20MSFT was completed 3-10 days prior to the start of academy (depending on the class schedule), while the 2.4-km run was completed within the first week of academy. Prior to the 20MSFT, each recruit's age, height, and body mass were recorded. Height was measured barefoot using a portable stadiometer (Seca, Hamburg, Germany), while body mass was recorded by electronic digital scales (Health o Meter, Neosho, Missouri). The 20MSFT was conducted outdoors on an asphalt surface at the LEA's training facility. Testing typically occurred between the hours of 0900-1400 depending on recruit availability, and recruits typically did not eat in the 2-3 hours prior to their testing session as they were completing employee-specific documentation for the LEA. The 2.4-km run was conducted between the hours of 0500-0700 depending on scheduled physical training sessions during academy, and was completed on an outdoor dirt athletics track. The weather conditions for testing were typical of the climate of southern California during a calendar year. Although conducting testing outdoors is not ideal, there was no indoor facility available and these procedures were adopted by staff from the LEA at all levels (i.e., during the hiring process, for recruits during academy, and for incumbents during skills refresher programs). 


\section{0-m Multi-Stage Fitness Test (20MSFT)}

Standard procedures were adopted for the 20MSFT. Recruits were required to run back and forth between two lines spaced $20 \mathrm{~m}$ apart, which were indicated by markers. The running speed for this test was standardized by pre-recorded auditory cues (i.e., beeps) played from an iPad handheld device (Apple Inc., Cupertino, California) connected via Bluetooth to a portable speaker (ION Block Rocker, Cumberland, Rhode Island). The speaker was located in the center of the running area, and positioned such that it would not interfere with the recruits. The test was terminated when the recruit was unable to reach the lines twice in a row in accordance with the auditory cues, or via voluntary cessation, and was scored according to the final stage the recruit was able to achieve. The stage was used to calculate the total number of completed shuttles. To reiterate the external pacing required for the 20MSFT, Table 1 details the different levels, number of shuttles per level, and the running speed required at each level. $\dot{\mathrm{V}}_{2 \max }$, measured in milliliters per $\mathrm{kg}$ body mass per minute $\left(\mathrm{ml} \cdot \mathrm{kg}^{-1} \cdot \mathrm{min}^{-1}\right)$, was estimated for each recruit based on the table from Ramsbottom et al. (36).

\section{***INSERT TABLE 1 ABOUT HERE***}

\section{4-km (1.5-mile) Run}

The recruits completed six laps around the 400-m track at the LEA training facility and were instructed to run this distance as quickly as possible. The run time was recorded for each recruit on a handheld stopwatch to the nearest $0.10 \mathrm{sec}$. Time for the $2.4-\mathrm{km}$ run was reported in minutes: seconds (min: s). $\dot{\mathrm{VO}}_{2 \max }$ was estimated for male and female recruits via the following equations developed by George et al. (15), which have been used previously for tactical populations (27): 
Male $\dot{\mathrm{VO}}_{2 \max }\left(\mathrm{ml} \cdot \mathrm{kg}^{-1} \cdot \mathrm{min}^{-1}\right)=91.736-(0.1656 \times$ body mass $)-(2.767 \times 2.4 \mathrm{~km}$ run time in min).

Female $\dot{\mathrm{VO}}_{2 \max }\left(\mathrm{ml} \cdot \mathrm{kg}^{-1} \cdot \mathrm{min}^{-1}\right)=88.020-(0.1656 x$ body mass $)-(2.767 \times 2.4 \mathrm{~km}$ run time in $\min )$.

\section{Statistical Analysis}

Statistical analyses were processed using the Statistics Package for Social Sciences (Version 24; IBM Corporation, New York, USA). Descriptive data (mean \pm standard deviation [SD]; 95\% confidence intervals $[\mathrm{CI}]$ ) were calculated for all recruits, males, and females for the 2.4$\mathrm{km}$ run time, 20MSFT shuttles, and estimated $\dot{\mathrm{VO}}_{2 \max }$ from each test. Independent samples ttests were used to calculate any between-sex differences in the 2.4-km run and 20MSFT, with significance set at $p<0.05$ a priori. Paired samples t-tests $(p<0.05)$ were used to compare the estimated $\dot{\mathrm{V}} \mathrm{O}_{2 \max }$ from calculated from the 2.4-km run and 20MSFT. Effect sizes $(d)$ were also calculated for these comparisons, where the difference between the means was divided by the pooled SD (9). A $d$ less than 0.2 was considered a trivial effect; 0.2 to 0.6 a small effect; 0.6 to 1.2 a moderate effect; 1.2 to 2.0 a large effect; 2.0 to 4.0 a very large effect; and 4.0 and above an extremely large effect $(18)$. Pearson's correlations $(p<0.05)$ and linear regression scatter plots calculated relationships between $2.4-\mathrm{km}$ run time and 20MSFT shuttle score, for all recruits and each sex. The correlation $(r)$ strength was designated as: an $r$ between 0 to 0.3 , or 0 to -0.3 , was considered small; 0.31 to 0.49 , or -0.31 to -0.49 , moderate; 0.5 to 0.69 , or -0.5 to -0.69 , large; 0.7 to 0.89 , or -0.7 to -0.89 , very large; and 0.9 to 1 , or -0.9 to -1 , near perfect for relationship prediction (17). 


\section{RESULTS}

The descriptive data for the 2.4-km run and 20MSFT are shown in Table 2. Males were 9\% faster in the $2.4-\mathrm{km}$ run, and completed $15 \%$ more shuttles in the $20 \mathrm{MSFT}$, compared to the females. There were significant differences between the males and females for both the 2.4-km run time and 20MSFT shuttles, and the corresponding estimated $\mathrm{VO}_{2 \max }$ from each test. The differences between the sexes for the 2.4-km run had moderate effects, while the 20MSFT had small effects. The estimated $\dot{\mathrm{VO}}_{2 \mathrm{max}}$ calculated from the $2.4-\mathrm{km}$ run were significantly $(p<$ 0.01) greater than those for the 20MSFT for all recruits, males, and females, and all effects were very large $(d=2.07,2.13$, and 2.11 , respectively).

\section{***INSERT TABLE 2 ABOUT HERE***}

With regards to the correlation analysis, the $2.4-\mathrm{km}$ run time had large relationships with the 20MSFT shuttles for all recruits $(r=-0.57)$, males $(r=-0.55)$, and females $(r=-0.60)$. Each relationship indicated that a faster $2.4-\mathrm{km}$ run related to a greater number of $20 \mathrm{MSFT}$ shuttles. Nevertheless, the $r^{2}$ values from the regression equations for all recruits $\left(r^{2}=0.32\right.$; Figure 1), males $\left(r^{2}=0.30\right.$; Figure 2$)$ and females $\left(r^{2}=0.37\right.$; Figure 3$)$ were relatively low.

\footnotetext{
***INSERT FIGURE 1 ABOUT HERE***

***INSERT FIGURE 2 ABOUT HERE***

***INSERT FIGURE 3 ABOUT HERE***
}

\section{DISCUSSION}

This study investigated sex differences and relationships between the 2.4-km run and 20MSFT in law enforcement recruits. The results from this study provided some support to the 
hypotheses, but also some contrary findings. Male recruits were significantly better compared to female recruits in the 2.4-km run and 20MSFT, although the effect size for the 20MSFT difference was smaller. There was a significant relationship between these tests for male and female recruits; however, the estimated $\dot{\mathrm{V}}_{2 \max }$ for each test were significantly different, and the strength of the predictive equations for the 2.4-km run and 20MSFT were relatively low. These results indicate that there was limited transferability between the two tests specific to law enforcement recruits. These data have important implications for LEA training staff and TSAC-F. This is especially true for those staff that may transition towards using the 20MSFT, due to its potential better match for the aerobic demands of specific law policing job tasks $(4,8,23,37)$.

Incumbent male law enforcement officers tend to perform better than female officers in the 2.4-km run (26) and 20MSFT (12). The data from this study supported these studies. This is to be expected, as males exhibit greater power and work efficiency in aerobic tasks compared to females (35), which can be in part related to differences in lean body mass which influence aerobic capacity (19). Nonetheless, LEA command staff should attempt to select fitness tests that do not adversely discriminate based on sex (3). This also relates to one of the reasons why $2.4-\mathrm{km}$ run time $(7,8,10,12,25-27,32,38,42)$ or $20 \mathrm{MSFT}$ shuttle number $(4,11,12,30,33,34,37)$ is used as the metric for aerobic fitness in law enforcement populations; the estimated $\dot{\mathrm{V}}_{2 \max }$ can be effected by the sex of the individual (15). Further, the data from this study indicated there was a small effect for the between-sex difference in the number of 20MSFT shuttles, as opposed to the moderate effect for the $2.4-\mathrm{km}$ run time, which may suggest that the 20MSFT had less disparate impact than the 2.4-km in the this sample. This may have been influenced by the disparate sample size for each sex, although this is typical of law enforcement research $(7,8,12,23,26)$. These results could also indicate that the physiological qualities required for the 20MSFT (i.e., aerobic capacity and high-intensity 
running ability) were more similar between the male and female recruits, and may be reflective of the recruit's training preparation. The staff from the LEA in this study has historically focused on long, slow distance running during academy training (6). If recruits physically prepared for this outcome, 20MSFT test performance may have been influenced more regardless of sex. These results are important to note, especially given the estimated $\dot{\mathrm{V}} \mathrm{O}_{2 \max }$ comparisons, correlations, and linear regression data.

There was a significant correlation between the 2.4-km run and 20MSFT in law enforcement recruits, which is similar to test data from UK military personnel (44). However, Wilkinson et al. (44) found $r^{2}$ values of 0.83-0.85 in regression equations for male and female Parachute regiment cadets, officer cadets, and non-infantry recruits. These data denote that between $83-85 \%$ of the variance was explained between the $2.4-\mathrm{km}$ run and 20MSFT, and strong predictive equations could be generated between the tests. In this study, while there were moderate-to-large correlations between the 2.4-km run and 20MSFT for male and female recruits, the $r^{2}$ values $\left(r^{2}=0.30-0.37\right)$ indicated that only $30-37 \%$ of the variance was explained between these tests. This meant that the predictive equations that were generated between the 2.4-km run and 20MSFT were not strong. Furthermore, the estimated $\dot{\mathrm{VO}}_{2 \max }$ from the 2.4-run was significantly greater than that for the 20MSFT in the law enforcement recruits, with large effect sizes. The recruits may have had greater familiarity with the $2.4-\mathrm{km}$ run than the 20MSFT, and the running demands associated with both assessments, contributing to the greater estimated $\dot{\mathrm{VO}}_{2 \max }$. Aandstad et al. (1) has noted that the 20MSFT may be influenced by learning effects in Norwegian Home Guard soldiers. Nonetheless, Aandstad et al. (1) also stated that the 20MSFT was still reliable and any differences in the estimated $\dot{\mathrm{VO}}_{2 \max }$ was of minor importance for most practical purposes. The results from this study indicate that the higher running intensity induced in the 20MSFT via the running speed increases, as well as the 
greater requirement for continued direction changes, may limit transferability between the two tests in law enforcement recruits.

It is important to discuss the implications of the transferability between the two tests specific to law enforcement recruits, especially considering the results of Wilkinson et al. (44). As noted previously, the training staff from this LEA emphasized long, slow distance running during their academy (6), operating via a 'one-size-fits-all' model $(6,29,33)$. Anecdotally, recruits prepared for this by completing high volumes of steady-state running during the leadup to academy. In moderately trained males, Helgerud et al. (16) illustrated that sprint running training using work: rest ratios of either $15 \mathrm{~s}$ x $15 \mathrm{~s}$ for 47 repetitions, or $4 \mathrm{~min} \times 4 \mathrm{~min}$, at 90$95 \%$ of maximum heart rate significantly improve maximal aerobic capacity. Both of these methods were superior to continuous running for $24-45 \mathrm{~min}$ at $70-85 \%$ of maximum heart rate. Cavar et al. (5) found that 20MSFT could be improved to a greater extent in college-aged men by long high-intensity ( $\sim 3 \times 3$ min work: rest ratios at $90-95 \%$ maximal shuttle-run speed [MSS] determined from the 20MSFT) and short high-intensity ( $\sim 15$ repetitions of $10 \mathrm{~s}$ x $10 \mathrm{~s}$ work: rest ratios at 115-120\% MSS) interval training compared to continuous training (35 min of continuous shuttle running at 70\% MSS). These adaptations were in part linked to the time spent above lactate threshold in the high-intensity protocols (5). It could be expected that sprint interval training methods similar to that presented by Helgerud et al. (16) and Cavar et al. (5) would be more beneficial to enhancing 20MSFT performance. If recruits did not complete this type of training prior to academy, this could mean that while they may be aerobically conditioned, the capacity to sustain high-intensity efforts is less optimal $(5,40)$. Indeed, this would have impacted the estimated $\dot{\mathrm{V}} \mathrm{O}_{2 \max }$ derived from the 20MSFT, which was much lower than that for the $2.4-\mathrm{km}$ run. This is especially pertinent considering many policing job tasks demand high-intensity, externally-paced activity $(4,8,23)$, in addition to the benefits for greater 
aerobic fitness as measured by the 20MSFT and load carriage performance in specialist police officers (37).

The differences in direction change requirements should also be addressed. The 20MSFT requires a $180^{\circ}$ turn every $20 \mathrm{~m}$, in addition to deceleration and acceleration skills. These types of actions require lower-body strength, and the ability to tolerate high braking forces during the direction change, followed by the efficient generation of propulsive forces to accelerate $(13,39)$. Conversely, the $2.4-\mathrm{km}$ run, by having fewer direction changes, may place less stress on the musculoskeletal system. Moreno et al. (30) noted this when comparing a 300$m$ run to the 20MSFT in incumbent officers. The difference in direction change demands would have influenced test performance for the recruits (i.e., the 20MSFT was likely more stressful for recruits) (5), and contributed to the lower estimated $\dot{\mathrm{VO}}_{2 \max }$ for this test. Future research should also analyze the relationships between the 20MSFT and tests of change-of-direction speed and agility law enforcement populations. Cesario et al. (7) found a small but significant $(r=0.23)$ and non-significant $(r=0.20)$ relationship between the 2.4-km run and 75-yard pursuit run (a test designed to simulate a foot pursuit) in male and female law enforcement recruits, respectively; the 20MSFT could demonstrate different relationships. Nonetheless, should an agency adopt the 20MSFT after using the 2.4-km run as a hiring standard, or use this test as a fitness marker during academy, they should also ensure correct training advice and appropriate training methods to enhance high-intensity running capacity and aerobic fitness. This should involve high-intensity running and sprint interval training $(5,16)$, and movement technique coaching and strength training to allow for efficient direction changes $(13,39)$. Failure to do so could result in less-than-optimal performance in the 20MSFT for candidates to the LEA or incoming recruits, which could adversely affect future employment.

There are certain study limitations that should be noted. This study analyzed law enforcement recruits at the start of the academy training period. Data recorded by candidates 
prior to being hired by an LEA, or incumbent officers, may produce different data to that from the current research. Only two aerobic fitness tests were measured in this study, although both have been heavily featured in law enforcement research $(4,7,8,10-12,25-27,30,32-$ $34,37,38,42)$. Other tests, such as the $30-15$ intermittent fitness test, have been used to assess law enforcement recruit fitness (33) and predict injuries (31). The 2.4-km run time and shuttle number for the 20MSFT did not consider or correct for lean body mass in this study (2). However, this was done as TSAC-F and LEA staff typically use run times $(7,8,10,12,25-$ $27,32,38,42)$ and shuttle numbers $(4,11,12,30,33,34,37)$ to indicate aerobic fitness. $\dot{\mathrm{V}} \mathrm{O}_{2 \max }$ was not directly calculated, although the estimations used were established standards from the literature $(15,36)$. Within the context of these limitations, the results from this study suggested that the between-sex differences for the 20MSFT were less than that for the 2.4-km run. Furthermore, even with significant relationships between the tests, the predictive relationships were low. The 20MSFT induced a higher running intensity and continued direction changes, which may limit transferability with the $2.4-\mathrm{km}$ run in law enforcement recruits.

\section{PRACTICAL APPLICATIONS}

There are several practical applications that can be drawn from this research. The differences between male and female law enforcement recruits may not be as pronounced in the 20MSFT compared to the 2.4-km run, which has implications for adverse impact during the LEA hiring process (3). However, this could also be influenced by any training (e.g., sprint interval training vs. long, slow distance running) completed by candidates or recruits in preparation for pre-hire fitness tests or academy training, respectively. For agencies that decide to adopt the 20MSFT as their aerobic fitness test for hiring or academy assessment, they must provide appropriate technical advice (e.g., coaching on running and change-of-direction technique) and training (e.g., high-intensity sprint interval and strength training) to candidates and incoming recruits. 
Further investigation of the 20MSFT is required as to its applicability to indicate academy graduation or separation, how relationships may change with the $2.4-\mathrm{km}$ run after academy when the recruits should be more fit, and relationships with law enforcement-specific tasks.

\section{REFERENCES}

1. Aandstad, A, Holme, I, Berntsen, S, and Anderssen, SA. Validity and reliability of the 20 meter shuttle run test in military personnel. Mil Med 176: 513-518, 2011.

2. Bilzon, JL, Allsopp, AJ, and Tipton, MJ. Assessment of physical fitness for occupations encompassing load-carriage tasks. Occup Med 51: 357-361, 2001.

3. Birzer, ML and Craig, DE. Gender differences in police physical ability test performance. Am J Police 15: 93-108, 1996.

4. Brewer, J, Buckle, P, and Castle, P. The use of work place physiological measurements to establish the minimum fitness standards required for entry into the United Kingdom Police Service. J Athl Enhancement 2: doi:10.4172/2324-9080.1000121, 2013.

5. Cavar, M, Marsic, T, Corluka, M, Culjak, Z, Cerkez Zovko, I, Müller, A, Tschakert, G, and Hofmann, P. Effects of 6 weeks of different high-intensity interval and moderate continuous training on aerobic and anaerobic performance. J Strength Cond Res: doi:10.1519/JSC.0000000000002798, in press.

6. Cesario, KA, Moreno, MR, Bloodgood, AM, Dulla, JM, and Lockie, RG, Heart rate responses of a custody assistant class to a formation run during academy training, in Southwest American College of Sports Medicine's 37th Annual Meeting Long Beach, CA, USA 2017.

7. Cesario, KA, Dulla, JM, Moreno, MR, Bloodgood, AM, Dawes, JJ, and Lockie, RG. Relationships between assessments in a physical ability test for law enforcement: Is there redundancy in certain assessments? Int J Exerc Sci 11: 1063-1073, 2018. 
8. Cocke, C, Dawes, J, and Orr, RM. The use of 2 conditioning programs and the fitness characteristics of police academy cadets. J Athl Train 51: 887-896, 2016.

9. Cohen, J. Statistical Power Analysis for the Behavioral Sciences 2nd ed. Hillsdale, New Jersey: Lawrence Earlbaum Associates, 1988.

10. Dawes, JJ, Orr, RM, Siekaniec, CL, Vanderwoude, AA, and Pope, R. Associations between anthropometric characteristics and physical performance in male law enforcement officers: A retrospective cohort study. Ann Occup Environ Med 28: doi:10.1186/s40557-016-0112-5, 2016.

11. Dawes, JJ, Lindsay, K, Bero, J, Elder, C, Kornhauser, C, and Holmes, R. Physical fitness characteristics of high vs. low performers on an occupationally specific physical agility test for patrol officers. $J$ Strength Cond Res 31: 2808-2815, 2017.

12. Dawes, JJ, Orr, RM, Flores, RR, Lockie, RG, Kornhauser, C, and Holmes, R. A physical fitness profile of state highway patrol officers by gender and age. Ann Occup Environ Med 29: doi:10.1186/s40557-017-0173-0, 2017.

13. Dos'santos, T, Thomas, C, Jones, PA, and Comfort, P. Mechanical determinants of faster change of direction speed performance in male athletes. $J$ Strength Cond Res 31: 696-705, 2017.

14. Fernström, M, Fernberg, U, Eliason, G, and Hurtig-Wennlöf, A. Aerobic fitness is associated with low cardiovascular disease risk: the impact of lifestyle on early risk factors for atherosclerosis in young healthy Swedish individuals - the Lifestyle, Biomarker, and Atherosclerosis study. Vasc Health Risk Manag 13: 91-99, 2017.

15. George, JD, Vehrs, PR, Allsen, PE, Fellingham, GW, and Fisher, AG. VO2max estimation from a submaximal 1-mile track jog for fit college-age individuals. Med Sci Sports Exerc 25: 401-6, 1993. 
16. Helgerud, J, Hoydal, K, Wang, E, Karlsen, T, Berg, P, Bjerkaas, M, Simonsen, T, Helgesen, C, Hjorth, N, Bach, R, and Hoff, J. Aerobic high-intensity intervals improve VO2max more than moderate training. Med Sci Sports Exerc 39: 665-671, 2007.

17. Hopkins, W.G. A scale of magnitude for effect statistics. Retrieved January 9, 2016, from www.sportsci.org/resource/stats/index.html. 2013.

18. Hopkins, WG. How to interpret changes in an athletic performance test. Sportscience 8: 1-7, 2004.

19. Janssen, I, Heymsfield, SB, Wang, Z, and Ross, R. Skeletal muscle mass and distribution in 468 men and women aged 18-88 yr. $J$ Appl Physiol 89: 81-88, 2000.

20. Kodama, S, Saito, K, Tanaka, S, Maki, M, Yachi, Y, Asumi, M, Sugawara, A, Totsuka, K, Shimano, H, Ohashi, Y, Yamada, N, and Sone, H. Cardiorespiratory fitness as a quantitative predictor of all-cause mortality and cardiovascular events in healthy men and women: A meta-analysis. JAMA 301: 2024-2035, 2009.

21. Lee, DC, Sui, X, Artero, EG, Lee, IM, Church, TS, Mcauley, PA, Stanford, FC, Kohl, HW, 3rd, and Blair, SN. Long-term effects of changes in cardiorespiratory fitness and body mass index on all-cause and cardiovascular disease mortality in men: The Aerobics Center Longitudinal Study. Circulation 124: 2483-90, 2011.

22. Léger, LA, Mercier, D, Gadoury, C, and Lambert, J. The multistage 20 metre shuttle run test for aerobic fitness. J Sports Sci 6: 93-101, 1988.

23. Lockie, RG, Dawes, JJ, Balfany, K, Gonzales, CE, Beitzel, MM, Dulla, JM, and Orr, RM. Physical fitness characteristics that relate to Work Sample Test Battery performance in law enforcement recruits. Int $J$ Environ Res Public Health 15: doi:10.3390/ijerph15112477, 2018. 
24. Lockie, RG, Dawes, JJ, Orr, RM, Stierli, M, Dulla, JM, and Orjalo, AJ. An analysis of the effects of sex and age on upper- and lower-body power for law enforcement agency recruits prior to academy training. J Strength Cond Res 32: 1968-1974, 2018.

25. Lockie, RG, Stierli, M, Dawes, JJ, Cesario, KA, Moreno, MR, Bloodgood, AM, Orr, RM, and Dulla, JM. Are there similarities in physical fitness characteristics of successful candidates attending law enforcement training regardless of training cohort? J Trainol 7: 5-9, 2018.

26. Lockie, RG, Dawes, JJ, Kornhauser, CL, and Holmes, RJ. A cross-sectional and retrospective cohort analysis of the effects of age on flexibility, strength endurance, lower-body power, and aerobic fitness in law enforcement officers. J Strength Cond Res 33: 451-458, 2019.

27. Lockie, RG, Orr, RM, Stierli, M, Cesario, KA, Moreno, MR, Bloodgood, AM, Dulla, JM, and Dawes, JJ. The physical characteristics by sex and age for custody assistants from a law enforcement agency. $J$ Strength Cond Res: doi:10.1519/jsc.0000000000002452, in press.

28. Mayorga-Vega, D, Aguilar-Soto, P, and Viciana, J. Criterion-related validity of the 20M shuttle run test for estimating cardiorespiratory fitness: A meta-analysis. J Sports Sci Med 14: 536-547, 2015.

29. Moreno, MR, Cesario, KA, Bloodgood, AM, Dulla, JM, and Lockie, RG, Heart rate response of a custody assistant class to circuit training during the academy period, in Southwest American College of Sports Medicine's 37th Annual Meeting: Long Beach, CA, USA 2017.

30. Moreno, MR, Lockie, RG, Kornhauser, CL, Holmes, RJ, and Dawes, JJ. A preliminary analysis of the relationship between the multistage fitness test and 300-m run in law 
enforcement officers: Implications for fitness assessment. Int J Exerc Sci 11: 730-738, 2018.

31. Orr, R, Stierli, M, Hinton, B, and Steele, M, The 30-15 Intermittent Fitness Assessment as a predictor of injury risk in police recruits, in Australian Strength and Conditioning Association: Tactical Strength and Conditioning Rapid Fire: Melbourne, Vic, Australia 2013.

32. Orr, R, Dawes, JJ, Pope, R, and Terry, J. Assessing differences in anthropometric and fitness characteristics between police academy cadets and incumbent officers. $J$ Strength Cond Res: doi:10.1519/JSC.0000000000002328, in press.

33. Orr, RM, Ford, K, and Stierli, M. Implementation of an ability-based training program in police force recruits. $J$ Strength Cond Res 30: 2781-2787, 2016.

34. Orr, RM, Caust, E, B., H, and Pope, R. Selecting the best of the best: Associations between anthropometric and fitness assessment results and success in police specialist selection. Int J Exerc Sci 11: 785-796, 2018.

35. Pate, RR and Kriska, A. Physiological basis of the sex difference in cardiorespiratory endurance. Sports Med 1: 87-98, 1984.

36. Ramsbottom, R, Brewer, J, and Williams, C. A progressive shuttle run test to estimate maximal oxygen uptake. Br J Sports Med 22: 141-144, 1988.

37. Robinson, J, Roberts, A, Irving, S, and Orr, RM. Aerobic fitness is of greater importance than strength and power in the load carriage performance of specialist police. Int J Exerc Sci 11: 987-998, 2018.

38. Shusko, M, Benedetti, L, Korre, M, Eshleman, EJ, Farioli, A, Christophi, CA, and Kales, SN. Recruit fitness as a predictor of police academy graduation. Occup Med 67: $555-561,2017$. 
39. Spiteri, T, Cochrane, JL, Hart, NH, Haff, GG, and Nimphius, S. Effect of strength on plant foot kinetics and kinematics during a change of direction task. Eur J Sport Sci 13: 646-652, 2013.

40. Thomas, A, Dawson, B, and Goodman, C. The yo-yo test: reliability and association with a 20-m shuttle run and VO(2max). Int J Sports Physiol Perform 1: 137-149, 2006.

41. Tomazini, F, Pasqua, LA, Damasceno, MV, Silva-Cavalcante, MD, De Oliveira, FR, Lima-Silva, AE, and Bertuzzi, R. Head-to-head running race simulation alters pacing strategy, performance, and mood state. Physiol Behav 149: 39-44, 2015.

42. Violanti, JM, Ma, CC, Fekedulegn, D, Andrew, ME, Gu, JK, Hartley, TA, Charles, LE, and Burchfiel, CM. Associations between body fat percentage and fitness among police officers: A statewide study. Saf Health Work 8: 36-41, 2017.

43. Wilkinson, DM, Blacker, SD, Richmond, VL, Rayson, MP, and Bilzon, JL. Relationship between the 2.4-km run and multistage shuttle run test performance in military personnel. Mil Med 179: 203-207, 2014.

44. Wilkinson, DM, Blacker, SD, Richmond, VL, Rayson, MP, and Bilzon, JLJ. Relationship between the $2.4-\mathrm{km}$ run and multistage shuttle run test performance in military personnel. Mil Med 179: 203-207, 2014.

45. Zimmerman, FH. Cardiovascular disease and risk factors in law enforcement personnel: A comprehensive review. Cardiol Rev 20: 159-166, 2012.

\section{FIGURE LEGEND}

Figure 1: Regression scatter plot for all recruits between the 2.4-km run and 20MSFT.

Figure 2: Regression scatter plot for male recruits between the 2.4-km run and 20MSFT.

Figure 3: Regression scatter plot for female recruits between the 2.4-km run and 20MSFT. 
Table 1: 20MSFT levels, number of shuttles per level, and time (seconds; s) and running speed (meters per second; m/s) for each shuttle.

\begin{tabular}{|c|c|c|c|}
\hline Level & Shuttles & Time per Shuttle (s) & Running Speed $(\mathrm{m} / \mathrm{s})$ \\
\hline 1 & 7 & 9.00 & 2.22 \\
\hline 2 & 8 & 8.00 & 2.50 \\
\hline 3 & 8 & 7.58 & 2.64 \\
\hline 4 & 9 & 7.20 & 2.78 \\
\hline 5 & 9 & 6.86 & 2.91 \\
\hline 6 & 10 & 6.55 & 3.05 \\
\hline 7 & 10 & 6.26 & 3.19 \\
\hline 8 & 11 & 6.00 & 3.33 \\
\hline 9 & 11 & 5.76 & 3.47 \\
\hline 10 & 11 & 5.54 & 3.61 \\
\hline 11 & 12 & 5.33 & 3.75 \\
\hline 12 & 12 & 5.14 & 3.89 \\
\hline 13 & 13 & 4.97 & 4.02 \\
\hline 14 & 13 & 4.80 & 4.17 \\
\hline 15 & 13 & 4.65 & 4.30 \\
\hline 16 & 14 & 4.50 & 4.44 \\
\hline 17 & 14 & 4.36 & 4.59 \\
\hline 18 & 15 & 4.24 & 4.72 \\
\hline 19 & 15 & 4.11 & 4.87 \\
\hline 20 & 16 & 4.00 & 5.00 \\
\hline 21 & 16 & 3.89 & 5.14 \\
\hline
\end{tabular}


Table 2: Descriptive data (mean $\pm \mathrm{SD} ; 95 \% \mathrm{CI}$ ) for all, male, and female LEA recruits in the 2.4-km run and 20MSFT. The $p$ value and $d$ statistic represent comparisons between the sexes.

\begin{tabular}{|c|c|c|c|c|c|}
\hline & All $(n=550)$ & Males $(n=463)$ & Females $(\mathrm{n}=87)$ & $p$ value & $d$ \\
\hline 2.4-km run (min: s) & $11: 49 \pm 1: 26(11: 41-11: 56)$ & $11: 38 \pm 1: 24(11: 30-11: 46)$ & $12: 48 \pm 1: 11(12: 33-13: 03)^{*}$ & $<0.01$ & 0.90 \\
\hline $\begin{array}{l}\text { 2.4-km run estimated } \\
\dot{\mathrm{V}} \mathrm{O}_{2 \max }\left(\mathrm{ml} \cdot \mathrm{kg}^{-1} \cdot \mathrm{min}^{-1}\right)\end{array}$ & $45.07 \pm 4.82(44.67-45.48)$ & $45.70 \pm 4.70(45.27-46.13)$ & $41.73 \pm 3.99(40.88-42.58)^{*}$ & $<0.01$ & 0.91 \\
\hline 20MSFT (no. of shuttles) & $51 \pm 17(50-53)$ & $53 \pm 17(51-54)$ & $46 \pm 15(43-49)^{*}$ & $<0.01$ & 0.44 \\
\hline $\begin{array}{c}\text { 20MSFT estimated } \\
\dot{\mathrm{V}} \mathrm{O}_{2 \max }\left(\mathrm{ml} \cdot \mathrm{kg}^{-1} \cdot \mathrm{min}^{-1}\right)\end{array}$ & $34.34 \pm 5.53(33.88-34.80) \S$ & $34.67 \pm 5.62(34.16-35.19) \S$ & $32.58 \pm 4.65(31.59-33.57)^{*} \S$ & $<0.01$ & 0.41 \\
\hline
\end{tabular}

* Significantly $(p<0.05)$ different from the males.

$\S$ Significantly $(p<0.05)$ different from the $\dot{\mathrm{V}} \mathrm{O}_{2 \max }$ estimated from the 2.4-km run. 